\title{
Tese

\section{MOBILIZAÇÃO JORNALÍSTICA NOS ANOS 70: A IMPRENSA ALTERNATIVA COMO MOVIMENTO SOCIAL}

\section{Vaniucha de Moraes ${ }^{1}$}

\section{RESGATE HISTÓRICO DA IMPRENSA ALTERNATIVA}

No Brasil existiram cerca de 150 jornais alternativos entre os anos de 1964 e 1980 de acordo com a extensa recensão realizada por Bernardo Kucinski a respeito dos periódicos da imprensa alternativa. Esta modalidade de imprensa, que também recebeu a alcunha de "imprensa nanica", teve como motivações a vontade das esquerdas de 1960 e 1970 de protagonizar as transformações que postulavam e a busca por espaços alternativos à grande imprensa e à universidade por parte dos jornalistas e intelectuais. Para Kucinski, são a oposição ao regime e as limitações à produção intelectual e jornalística as bases da articulação entre jornalistas, intelectuais e ativistas políticos (2003, p. 16).

A obra de Kucinski relata a trajetória da imprensa alternativa desde os títulos iniciais no final dos anos 60 ao apogeu, entre 1975 e 1976, quando circularam em âmbito nacional oito grandes alternativos, notadamente os jornais $O$ Pasquim, Crítica e Opinião do Rio de Janeiro; Ex, Movimento, e Versus de São Paulo; Brasil Mulher de Londrina e São Paulo, e Coojornal de Porto Alegre (2003, p. 139). O autor relata que as experiências alternativas em sua maioria foram efêmeras e seus jornais duraram no máximo de 2 a 3 anos, sendo que nenhum sobreviveu ao regime militar.

Kucinski realizou um resgate histórico envolvendo a criação e difusão dos jornais alternativos. De acordo com a categorização criada pelo pesquisador, os

\footnotetext{
${ }^{1}$ Doutoranda vinculada ao Programa de Pós-Graduação em Sociologia Política da Universidade Federal de Santa Catarina. Mestre em Jornalismo pela UFSC. Pesquisadora de temáticas como: História da imprensa e jornalistas intelectuais brasileiros; jornalismo e literatura. Contato: ucha8@outlook.com
} 




alternativos podem ser divididos em fases de acordo com as motivações e o caráter da articulação entre seus protagonistas e deles com a sociedade civil. Foram identificadas pelo menos 7 gerações distintas de jornais alternativos. A primeira fase do ciclo, do lançamento de Pif-Paf em junho de 1964 até o fim da Folha da Semana em 1966, foi marcada pelo impacto do golpe de abril de 1964. A segunda geração surgiu em 1967 sob a égide da revolução cubana e a proposta de uma guerrilha continental, momento em que surgiram $O$ sol, Poder Jovem e Amanhã. Em 1968, houve um intervalo preenchido com as passeatas do movimento estudantil fruto da reverberação do maio de 1968 na França em sinergia com as próprias questões nacionais. Segundo o autor, com o esmorecimento das manifestações e a partir de 1969 vários jornalistas e intelectuais começaram a se mobilizar dando origem a duas fases subsequentes, marcadas pela resistência político-cultural nas quais se destacaram O Pasquim e Opinião. Entre 1971 e 1972 aconteceu a quinta fase caracterizada pelo tratamento de assuntos sob o viés do humor e pelo uso dos cartoons estrangeiros em Grilo e Balão, período em que ganharam visibilidade cartunistas como Laerte, Angeli e os irmãos Chico e Paulo Caruso. No ano de 1974 ganharam liberdade os primeiros presos políticos e os jornais alternativos incharam de colaboradores. Em 1976 há uma sexta fase sob o signo da crise do milagre econômico e dela nasceram grandes projetos alternativos como Versus e Movimento. Segundo relato de Kucinski, da crise ocorrida após o assassinato do jornalista Vladimir Herzog em outubro de 1975, foram produzidos jornais como De Fato e Coojornal. O pesquisador lembra que nesse momento se iniciou uma onda crescente de diversificação temática com o aparecimento de alternativos regionais e feministas. Na sequência, o processo de diversificação temática soma-se à campanha pela anistia, e dessa aliança se produziram os jornais Repórter, Resistência e Maria Quitéria. De acordo com o relato do pesquisador, após esse período, ocorre a adoção do modelo alternativo pelos estudantes das escolas de comunicação e estes alunos começam a produzir os jornais da última geração de alternativos, periódicos ligados aos movimentos populares como o jornal basista Batente.

A categorização elaborada por Kucinski apontou a existência de três linhagens distintas de acordo com seus protagonistas. Duas dessas linhagens foram influenciadas pelo jornalismo da revista Realidade (1966/1976) uma vez que parte dos jornalistas daquela publicação migrou para a imprensa alternativa com o recrudescimento do 


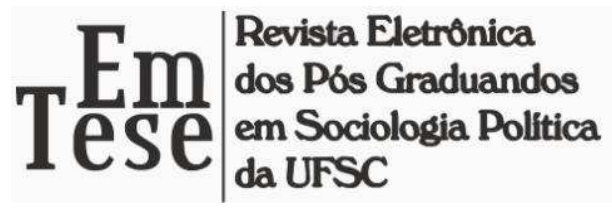

regime militar. Uma das linhagens foi a vertente existencial e antidoutrinária formada por dissidentes da Ação Popular (AP) que lançaram jornais como Bondinho, Grilo, Fotochoq, Ex, Extra-Realidade Brasileira e Domingão; a outra linhagem foi a vertente política considerada a mais prolífera, produtora de Opinião, Movimento, Assuntos, Amanhã, Em Tempo, e posteriormente Brasil Extra e Retrato do Brasil. Por fim, a terceira linhagem foi constituída pelos cartunistas cariocas Ziraldo, Jaguar, Millôr Fernandes e Henfil que participaram de Pif-Paf, O Pasquim, Flor do Mal e Enfim.

O ocaso da imprensa alternativa começa a partir dos anos de 1980 e 1981 quando então pararam de circular todos os jornais que estavam em atividade entre 1977 e 1979 à exceção de $O$ Pasquim, Resistência e Em Tempo que já nessa época haviam abandonado o padrão alternativo.

Uma das causas para o declínio foi a ingerência econômica. Havia uma aversão a questões relativas à administração e comercialização. A ausência de uma organização administrativa esteve calcada em uma aversão ao espírito capitalista e ao lucro, ou seja, embora jornais, como $O$ Pasquim, alcançassem um significativo índice de vendagem e houvesse lucro, este não se replicava uma vez que a razão de ser desses jornais era a aglutinação de intelectuais e jornalistas e a luta pelo exercício da liberdade de expressão ainda que sob a vigência da censura.

Outro fator que explica o enfraquecimento da imprensa alternativa foram os chamados "rachas" entre os grupos de esquerda dos quais os jornalistas faziam parte e que se desdobraram em inúmeras cisões dentro dos jornais. Alternativos significativos foram vitimados pelas idiossincrasias da cultura de esquerda. Uma forma peculiar de alienação foi instaurada nesses jornais e muitos jornalistas passaram de sujeitos do processo a instrumentos de manipulação, fruto da lógica de funcionamento dos partidos e assim, "de traço ideológico o sectarismo tornou-se linguagem, cultura, hábito e finalmente uma ética" (KUCINSKI, 2003, p. 26), por consequência, os coletivos foram desmantelados em função das divergências político-partidárias. O hermetismo que desconsiderava a abertura para um público leitor mais abrangente inclusive dentro da própria esquerda, pode ter sido um dos fatores que contribuíram para esse declínio, mas sozinho não o explica totalmente, como se depreende das reflexões do jornalista pesquisador Bernardo Kucinski.

Uma série de fatores causou o fim dos jornais alternativos. Nesse intercurso, a 


\section{Tese}

repressão, os atentados às bancas de revistas, os sequestros de edições e a censura prévia foram causas impactantes, mas ainda não foram as responsáveis diretas. Tornou-se lugar comum associar o fim da ditadura militar ao fim dos jornais alternativos, entretanto, para Kucinski, que em seu trabalho buscou responder a pergunta sobre o porquê do desaparecimento repentino dos alternativos, a resposta não está vinculada apenas ao fim da ditadura militar. Muitos dos alternativos sumiram quando houve crises no interior dos partidos em tempos de abertura política e institucionalização dos movimentos sociais. Segundo o autor, a desagregação dos alternativos ancorados em partidos de esquerda foi uma das consequências do processo de abertura política, isso porque a imprensa alternativa não foi uma substituta da imprensa partidária, mas do próprio partido como espaço de articulações e com a abertura essa função se tornou dispensável uma vez que, "os partidos se organizavam abertamente. Abandonam a imprensa alternativa, na qual precisavam conviver forçosamente com outros partidos e facções, e lançam seus próprios jornais a partir de junho de 1979” (KUCINSKI, 2003, p. 195).

A união desses fatores causou o esvaziamento da imprensa alternativa. Em tempos de abertura, os jornalistas começaram a se aproveitar dos espaços de atuação criados pela grande imprensa que soube apropriar-se do padrão alternativo. No entanto, as experiências de transposição do estilo alternativo para grande imprensa foram efêmeras, pois após a greve dos jornalistas em 1979 muitos desses jornalistas foram expurgados das redações. Nesse novo cenário um novo tipo de jornalismo começava a se configurar em função da entrada para o mercado de trabalho dos egressos das faculdades de comunicação. Nascia nesse momento um jornalismo que se pretendia mais técnico e profissional e menos dogmático. Em síntese, pode-se considerar que para o autor de "Jornalistas e Revolucionários", a ditadura não foi a única razão da existência nem do fim dos jornais alternativos, para ele:

A extinção dos alternativos pode ser sintomática de algo mais profundo do que simplesmente, ou apenas, a lógica do regime autoritário. Pode ter sido sintomática do fim de outros ciclos, cujo ocaso se confundiu com a ditadura brasileira sem ter com ela uma relação direta. A morte de propostas éticas de transformação social, da crença da realização pessoal através da ação coletiva e comunitária (KUCINSKI, 2003, p. 28). 


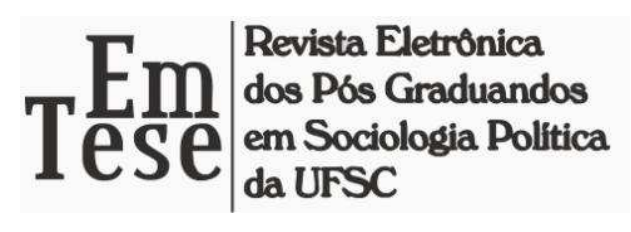

A história da imprensa alternativa contada por Kucinski conduz ao raciocínio de que existem inúmeras confluências entre o que se pensava e o que produzia cientificamente a respeito dos movimentos sociais e o que acontecia na prática dentro desses movimentos. É possível supor que as transformações e reorientações nos movimentos sociais talvez fossem apreendidas pelos pensadores contemporâneos a essas atuações. Aqui buscarei não apenas refletir sobre a imprensa alternativa como um movimento social, mas também analisá-la em seu contexto espaço-temporal. Os desdobramentos do contexto sócio-histórico, tanto em âmbito nacional como internacional são observados sob a perspectiva da transição da influência do paradigma marxista para o paradigma dos novos movimentos sociais. Nesse trabalho pretendo postular que no transcorrer de sua história os jornais da imprensa alternativa seguiram um caminho que partiu de uma maior ortodoxia para uma diversificação da temática ideológica seguindo uma trajetória em paralelo com as teorias cujo foco foram os movimentos sociais.

\section{A IMPRENSA ALTERNATIVA COMO MOVIMENTO SOCIAL}

A imprensa alternativa deu visibilidade aos movimentos sociais que agiam em seus bastidores nas décadas de 1960 e 1970 ou foi em si um movimento social? Responder esse questionamento se faz importante para compreender a participação dessa modalidade de imprensa no processo de redemocratização. Significa supor a possibilidade da imprensa alternativa poder ter substituído as funções que a grande imprensa desempenharia em situações democráticas regulares e também a possibilidade de ter substituído a atuação partidária de oposição em um momento de exceção.

Mas o que é um movimento social? A definição sobre movimento social não é um ponto pacífico nem definitivo nas teorias existentes sobre o assunto. Existem várias teorias sobre o tema e definições. Sidney Tarrow que se debruçou sobre a história dos movimentos sociais procurou dar uma definição ao conceito de movimento social a partir da ideia de confronto político. Para Tarrow, o confronto político surge de uma reação às mudanças nas oportunidades e restrições políticas em que os participantes reagem a uma variedade de incentivos, sejam eles, materiais e ideológicos, partidários 


\section{$\mathrm{Em}^{20 m a n}$ \\ Tese da UFSC}

ou baseados no grupo, cujas reações podem ser de longa duração ou pontuais. Para ele, a partir dessas oportunidades e usando repertórios conhecidos de ação, pessoas usando recursos escassos podem agir de forma contenciosa ainda que eventualmente. Segundo o autor, um movimento social só pode ser considerado como tal somente quando tais ações se baseiam em densas redes sociais e estruturas conectivas e recorrem a quadros culturais consensuais e orientados para a ação, sendo que tais redes podem sustentar essas ações no conflito com opositores poderosos (TARROW, 2009, p. 27).

O conceito de Tarrow em contraste com o que já foi mencionado sobre os jornais alternativos pode levar à reflexão da imprensa alternativa como movimento social. Kucinski, destacado estudioso da imprensa alternativa, assim a definiu a partir de seus agentes:

Os protagonistas da imprensa alternativa de 1970 constituíam uma subcultura que se distinguia do grosso dos jornalistas e intelectuais pela sua disposição contestatória, pela sua propensão ao ativismo, pela sua intransigência intelectual e, em certa medida moral, pela afinidade com os motivos ideológicos que moviam os ativistas políticos (KUCINSKI, 2003, p. 36).

Podemos fazer duas apreciações do que precede: a primeira é que podemos sim falar que existiu uma rede social entre as experiências alternativas, pois havia conexões ideológicas e pessoais entre os projetos alternativos. Podemos inferir também que o que cimentava essa rede eram as causas políticas embasadas na contestação ao Estado autoritário e na afinidade ideológica. No entanto, as próprias divergências de facções dentro dessa ideologia foram responsáveis pela desarticulação de seus integrantes. Assim, podemos inferir que a rede colaborativa calcada nas ações coletivas estava frágil e por isso a imprensa alternativa esteve frágil como movimento social.

$\mathrm{O}$ estudo sobre ações coletivas remonta ao início do século XX nos Estados Unidos. A partir dos anos 60, em virtude do contexto histórico de efervescência revolucionária, diversos pesquisadores se lançaram à pesquisa sobre os movimentos sociais. O tema por isso conquistou status de objeto científico e foi alvo de várias teorias. Maria da Glória Gohn realizou uma ampla sistematização das principais teorias e os paradigmas correspondentes sobre os movimentos sociais. A autora reuniu uma série de autores e teorias em categorias de análise conforme divisão geográfico-espacial a fim de relacionar a criação de cada teoria e paradigma ao contexto em que foram 


\section{$\mathrm{Em}^{20+0}$ \\ Tese da UFSC}

concebidos. Ela abordou desde o paradigma norte-americano; passando pelos paradigmas europeus que se subdividem em duas abordagens, a marxista e a referente aos novos movimentos sociais; até o paradigma latino-americano no qual a autora se concentra. De acordo com a Gohn, as teorias que influenciaram o paradigma latinoamericano se identificaram com os paradigmas europeus. Nos anos 70 o predomínio foi da vertente marxista e nos anos 80 a abordagem dos novos movimentos sociais. Analisaremos, portanto, esses paradigmas que exerceram influência sob as teorias latino-americanas e em seguida apontaremos para as possíveis consonâncias com os movimentos sociais que ocorreram no âmbito da imprensa alternativa.

Sob a ótica marxista, os movimentos sociais estão relacionados aos processos de lutas sociais voltadas para transformação das condições existentes na realidade social. No paradigma marxista clássico a classe operária industrial tem primazia no processo de luta social e o movimento operário desempenha o papel de vanguarda nas transformações sociais. O movimento junto com o partido político e com os intelectuais orgânicos à classe operária teria uma missão na história: transformar a sociedade das desigualdades sociais em outra, sem opressão ou oprimidos. A classe operária seria o agente principal de um novo devir histórico por ser a negação de seu oponente básico: a burguesia (GOHN, 2004, p. 172).

O paradigma marxista clássico esteve no cerne dos movimentos sociais na América Latina, fato que também ocorreu no Brasil em especial naqueles jornais atrelados aos projetos políticos nacionais, categorizados como "jornais de frente política dentro do conjunto dos alternativos" (KUCINSKI, 2003). Jornais como Amanhã, Opinião e Movimento se caracterizaram pelo posicionamento assumidamente políticoideológico. Amanhã, por exemplo, nasceu em 1967 em São Paulo sob o imaginário da guerrilha e figurou entre os mais importantes da linhagem política. Segundo Kucinski, foi em Amanhã que se criou o mecanismo de "frente jornalística", no qual vários partidos de esquerda, mantendo seus jornais clandestinos ou de partido, se uniram na sustentação de um jornal (2003, p. 56). Amanhã foi produzido por estudantes ativistas políticos para ser lido por uma classe operária desarticulada pela opressão (2003, p. 61). Apesar de não termos dados suficientes que comprovem que o público leitor dos jornais da frente política fosse constituído ao menos em parte por operários, de acordo com a pesquisa de Kucinski, podemos constatar que alcançar o operário era um horizonte 


\section{Tese}

presente nos jornais da vertente política para a qual Amanhã foi uma referência em termos de padrão e proposta editorial.

Pode-se perceber que pairava entre os jornais o imaginário referente paradigma marxista clássico, no entanto no transcorrer de sua história foram geradas uma miríade de matizes simultaneamente ao processo de cisões das facções políticas e ao processo de mudança nas próprias condições políticas e sociais do Estado brasileiro. No que concerne ao trato com linguagem e difusão, no entanto, foi apenas com os jornais vinculados aos movimentos populares, a partir de 1977, que surgiu a preocupação com uma linguagem mais acessível ao público menos instruído formado por trabalhadores e moradores das periferias das grandes capitais.

Os periódicos ligados aos movimentos populares envolveram-se em lutas específicas, locais, de bairros, envolvendo uma população heterogênea. Muitos nasceram em cursos de comunicação social e foram criados por estudantes críticos dos grandes meios de comunicação de massa sendo pensados dentro das diretrizes da comunicação comunitária. Esses projetos vincularam-se aos movimentos de base como as Comunidades Eclesiais de Base e às greves operárias. Entre essas experiências Kucinski destacou o Jornal dos Bairros, Repórter da Região, ABCD Jornal, Repórter de Guarulhos e Jornal da Vila (2003, p. 146). Para Kucinski, é a partir desse conjunto de alternativos basistas nos quais os jornalistas se aproximaram dos movimentos de base ou sindicais articulados aos ativistas políticos que se pode considerar a própria imprensa alternativa como um movimento de base:

\footnotetext{
Um movimento de base jornalística, cuja reivindicação específica é a de praticar um determinado tipo de jornalismo possível apenas fora do mercado convencional. Distinguem-se dos alternativos portadores de projetos nacionais de transformação cuja primazia é o projeto nacional. Nesses jornais basistas a prática jornalística a ser alcançada é o seu próprio fim, sendo a transformação da sociedade um de seus valores referenciais. Prática que se apoia nos movimentos sociais e enfatiza a "contra-informação", como a informação que é negada do povo por parte da imprensa dominante (KUCINSKI, 2003, p. 156).
}

Os jornais vinculados aos movimentos populares podem ser reunidos àqueles que apresentaram propostas que diferiam dos alternativos ancorados a projetos políticos nacionais, tais exemplares se caracterizaram pelo interesse difuso e por encamparem 


\section{Tese}

lutas mais específicas tais como os jornais alternativos feministas e os ecologistas.

A difusão dos alternativos pautados pela diversidade temática ocorre paralelamente à adoção de um novo paradigma no campo de estudos dos movimentos sociais que começou a surgir em fins de 1970 e começo de 1980, o paradigma dos novos movimentos sociais. Esse conjunto de propostas teóricas parte da revisão do paradigma tradicional marxista então considerado inadequado para análise dos movimentos sociais que ocorreram na Europa a partir dos anos de 1960. Algumas características desse paradigma conseguem apontar para uma possível explicação para o processo ocorrido na imprensa alternativa. Entre as características citadas por Gohn, destaca-se a negação do marxismo como campo teórico capaz de dar conta da ação dos indivíduos e, por conseguinte, da ação coletiva da sociedade contemporânea. Esse novo paradigma elimina o sujeito histórico redutor da humanidade, predeterminado, configurado pelas contradições do capitalismo e formado pela "consciência autêntica" de uma vanguarda partidária. Ao contrário, o novo sujeito que surge é um coletivo difuso, não-hierarquizado, em luta contra discriminações de acesso aos bens da modernidade e, ao mesmo tempo, crítico de seus efeitos nocivos, a partir da fundamentação de suas ações e valores tradicionais, solidários, comunitários. Portanto, a nova abordagem elimina a centralidade de um sujeito específico e predeterminado e vê os participantes das ações coletivas como atores sociais (GOHN, 2004, p. 123).

A negação da predeterminação de um sujeito histórico foi concomitante à conquista de visibilidade de causas como a feminista, à luta em prol dos grupos negros e indígenas, as reivindicações das periferias, dos homossexuais e dos ambientalistas. Com relação à imprensa alternativa, embora seja evidente que desde fins da década de 1960 já existiam jornais alternativos ancorados em propostas editoriais apartidárias orientados por várias matizes temáticas - destaca-se desde os humorísticos precursores Pif-Paf de Millôr Fernandes e $O$ Pasquim, bem como os jornais da vertente existencial baseados na contracultura dos anos 70, Bondinho, Flor do Mal e Ex -, a diversificação temática acontece de uma forma mais efetiva e ampla a partir da segunda metade da década de 1970.

Entre os jornais feministas que começaram a atuar a partir de 1975 - muitos deles acumulando militâncias - se destacaram: Brasil Mulher, Nós Mulheres, Maria Quitéria e Mulherio. O Beijo de 1977 concentrou-se na reação à repressão sexual 




existente dentro da própria esquerda. Esse periódico desfechou o primeiro grande ataque à concepção de homossexualidade dos jornalistas de $O$ Pasquim. Posteriormente surgiu Lampião da Esquina, um jornal carioca cuja bandeira era abertamente a causa do homossexualismo e a defesa franca e aberta dos direitos das minorias sexuais. Entre os jornais de viés ecológico os que ganharam visibilidade durante o ano de 1977 foram o Paranapanema e Ecojornal, ambos contavam com o apoio empresarial e de entidades ecológicas nacionais e estrangeiras (KUCINSKI, 2003, p. 132). Com isso, se pode inferir que tais alternativos refletem a influência que os chamados novos movimentos sociais estavam exercendo na América Latina naquele momento.

Gohn relata em seu trabalho que em fins dos anos 80 os estudos sobre os movimentos sociais na América Latina eram predominantemente de natureza mais empírico-descritiva. Segundo ela, o que existia concretamente era um panorama diferenciado de lutas e movimentos sociais quando comparado com os movimentos europeus e norte-americanos, o que se constatava então era que havia muitas mobilizações massivas, mas pouca teorização sobre os próprios movimentos (2004, p. 211). No transcorrer da trajetória desses estudos a teoria da dependência e a teoria da marginalidade estrutural se aliaram a influência dos paradigmas europeus. Segundo a pesquisadora, no início foi soberana a influência teórica do paradigma marxista e isto se explica pela predominância deste paradigma nos meios acadêmicos nos anos 70 e pelos projetos concretos de luta para a redemocratização naquele período (2004, p. 216). Porém, ao longo dos anos 80 a abordagem marxista foi sendo substituída pela referente aos novos movimentos sociais que se posicionava em desacordo com relação às interpretações mais ortodoxas marxistas (GOHN, 2004, p. 217).

A proliferação dos estudos a respeito dos movimentos sociais no Brasil aconteceu no período ditatorial especialmente no momento em que havia um cenário de forte repressão às lutas sociais e alarde dos movimentos de redemocratização. Podemos deduzir que a onda de estudos sobre os movimentos populares acontece em consonância com a expansão dos próprios no país, dentre os quais podemos visualizar a própria imprensa alternativa. As lacunas e desajustes nesses estudos apontados por Gohn podem contribuir para um entendimento sobre essa questão, especialmente quando a autora define o que são os movimentos sociais. 


\title{
Tese
}

\begin{abstract}
Movimentos sociais são ações sociopolíticas construídas por atores sociais coletivos pertencentes a diferentes classes e camadas sociais, articuladas em certos cenários da conjuntura socioeconômica e política de um país, criando um campo político de força social na sociedade civil (...) Os movimentos geram uma série de inovações nas esferas pública (estatal e não-estatal) e privada; participam direta ou indiretamente da luta política de um país, e contribuem para o desenvolvimento e a transformação da sociedade civil e política (GOHN, 2004, p. 252).
\end{abstract}

Do trecho destacado vê-se a centralidade dada ao campo da política uma vez que a autora considera os movimentos sociais como expressões de poder da sociedade civil sendo por ela considerados como processos político-sociais. Para Gohn, os movimentos sociais "criam e desenvolvem um campo político de forças sociais na sociedade civil contribuindo para seu desenvolvimento político" (2004, p. 252), eles são "coletivos que no processo da ação socio-política desenvolvem uma identidade, de forma que se apresentam como atores coletivos" (GOHN, 2004, p. 252). Ao considera-los como processos políticos, podemos refletir sobre o presente objeto de análise. A imprensa alternativa foi atuante e sofreu influência direta do contexto ditatorial e da passagem para a abertura política, ela foi protagonista e coadjuvante nos processos de: institucionalização dos movimentos sociais; ascensão ao poder de lideranças políticas que ajudou a dar visibilidade; redemocratização brasileira, bem como, sofreu os desdobramentos da crise no paradigma marxista na década de 80 e posteriormente do próprio paradigma dos novos movimentos sociais na década de 90 .

Em síntese, a crise das vertentes de pensamento identificadas ao marxismo clássico e o declínio e fim dos jornais alternativos na década de 1980 têm uma forte ligação. Trata-se de algo curioso a passagem de uma maior ortodoxia nos alternativos políticos para ênfase em um revisionismo e apelo para uma diversidade temática no período subsequente. A questão que pretendo destacar é o fato da imprensa alternativa ser um movimento social predominantemente de orientação esquerdista e que por isso estava passível de sofrer as influências diretas de um contexto de turbulência que ocorria em âmbitos nacional e internacional. As repercussões da trajetória do paradigma marxista na imprensa alternativa - enquanto movimento social - podem ser observadas na transposição dos jornais da frente política para os jornais ligados a movimentos populares e na transposição desses para jornais da fase de diversificação temática. Observando-se que tais fases não foram estanques já que em cada período houve uma 


\section{$\mathrm{Em}$ da UFSC}

orientação ideológica predominante.

Ernesto Laclau e Chantal Mouffe podem contribuir para a reflexão sobre esse cenário de mudanças uma vez que propuseram uma alternativa para as esquerdas em crise na segunda metade da década de 80. Em "Hegemonia e estratégia socialista: para uma radicalização da democracia" os autores se dedicaram a atualizar e revisar as propostas marxistas diante de um mundo globalizado, neoliberal e pluralizado.

\section{IMPRENSA ALTERNATIVA NO PROCESSO DE REDEMOCRATIZAÇÃO}

A proposta de pensar a imprensa alternativa dos anos 70 como um movimento social, conduz a caminhos que implicam associá-la tanto aos movimentos que foram a ela contemporâneos como aos paradigmas que lhe serviram de inspiração. As análises a respeito dos movimentos sociais da década de 1970 elaboradas num período posterior são esclarecedoras para compreender o ocorrido na imprensa alternativa durante a redemocratização brasileira. A redemocratização foi um processo extenso e compreendeu o período entre o governo militar de Ernesto Geisel e sua proposta de abertura política "lenta e gradual"; o governo de João Batista Figueiredo no qual foi aprovada a Lei da Anistia em 1979; e a elaboração de uma Constituição em 1988 e as eleições diretas para presidente em 1989.

Pesquisadores que se propuseram a pensar a crise no pensamento de esquerda diante do processo de redemocratização dos países latino-americanos como Laclau e Mouffe são importantes para elucidar a trajetória da imprensa alternativa. Isso porque os projetos editoriais da imprensa alternativa dialogam com o paradigma marxista e o paradigma dos novos movimentos sociais. Sendo assim, o objetivo é analisar a repercussão da conjuntura intelectual, social e política no fim do ciclo alternativo em 1980.

Conforme exposto a transição do paradigma marxista clássico para o paradigma referente aos novos movimentos sociais reverberou na imprensa alternativa. Um traço importante dessa transposição de paradigmas foi o rompimento com a noção de sujeito, 


\section{$\mathrm{Em}^{20 m a n}$ \\ Tese da UFSC}

"enquanto unidade racional e transparente que transmite um significado homogêneo para o campo total da conduta do indivíduo, sendo a fonte de suas ações" (LACLAU, 1986, p. 4). Perante a complexidade das sociedades contemporâneas tornou-se insuficiente fazer análises sob a perspectiva da noção de sujeito bem como do conceito de "lutas de classe". Tais conceitos estanques se tornaram incapazes para apreender a lógica da construção identitária dos sujeitos. Retrospectivamente, podemos dizer que o antagonismo original personificado na oposição capitalista versus operário encerrava a ideia de um sujeito histórico privilegiado personificado na figura operário. Atualmente essa ideia se tornou obsoleta, pois não podemos considerar um sujeito revolucionário privilegiado capaz de transformar a sociedade em seu conjunto. Em virtude disso, a proposta da existência de múltiplas posições de sujeito tornou-se uma ferramenta conceitual importante.

Para Laclau é impossível se falar do agente social como se estivéssemos lidando com uma entidade unificada e homogênea, assim devemos contemplar esse agente em sua pluralidade o que significa considerar as várias posições de sujeito através dos quais o indivíduo é constituído. Dessa consideração provém a característica central dos novos movimentos sociais que reúne o conjunto de posições de sujeito tornados pontos de conflito e mobilização política (LACLAU, 1986, p. 5). Exemplificando, pode-se dizer que uma pessoa pode simultaneamente ser afiliada a algum partido político, simpatizante do movimento feminista, participar da coleta seletiva de lixo de seu bairro, fazer parte do grupo de pessoas que vai a concertos de rock e integrar-se à sua própria comunidade profissional. Em outras palavras, é reducionista considerar o sujeito através de um viés pré-determinado.

Segundo Laclau, as posições de sujeito são permeáveis e tal característica dá margem às articulações entre as posições de sujeito e as práticas articulatórias. Isso significa que conexões podem ser criadas entre indivíduos que se filiam a determinado ideário constituindo assim o que o autor denomina como práticas hegemônicas. É em virtude disso que podemos dizer que jornais como $O$ Pasquim, Bondinho, Extra Realidade Brasileira, Brasil Mulher, em determinado momento podiam reunir uma série de lutas de caráter emancipatório e democratizante ao agregar a contestação ao Estado autoritário às lutas feministas, anti-racistas e contra diversas formas de conservadorismo e autoritarismo. 


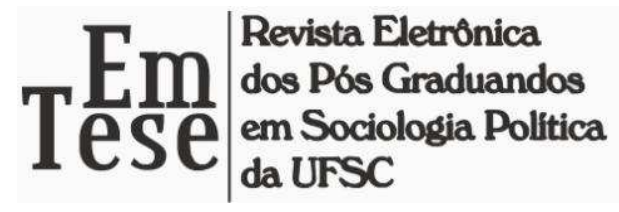

Um traço importante da obra de Laclau e Mouffe é a crítica que fazem ao termo "novos movimentos sociais". Podemos dizer que o termo teve em um primeiro momento a função de amalgamar uma série de lutas diversas, urbanas, ecológicas, antiautoritárias, anti-institucionais, feministas, anti-racistas, de minorias étnicas, regionais ou sexuais que foram costumeiramente distintas das lutas de classe. Diante da emergência da pluralidade de antagonismos os autores observaram que as articulações entre as distintas posições de sujeito podem gerar uma articulação hegemônica envolvendo valores e propostas democratizantes capazes de conflitar com a hegemonia do liberal conservadorismo. Nesse sentido os novos movimentos sociais estariam atrelados ao histórico de revoluções democráticas que remonta à Revolução Francesa e, portanto, o adjetivo "novos" não seria adequado.

\begin{abstract}
Lo que nos interessa de estos nuevos movimentos sociales no es, por tanto, su arbitraria agrupación en tanto que los opondría a los de classe, sino la novedad de los mismos, en tanto que través de ellos se articula esa rápida difusión de la conflitualidad social a relaciones más e más numerosas, que es hoy día característica de las sociedades industriales avanzadas. Esto es lo que intentaremos analisar a través de la problemática teórica presentada anteriormente, que nos llevará a concebir a esos movimentos com una extensión de la revolución democrática a toda una nueva serie de relaciones sociales (LACLAU;MOUFFE, 2004, p. 195).
\end{abstract}

A proposta elaborada por Laclau e Mouffe, para as esquerdas em crise, em meados da década de 80 é constituída por uma releitura crítica dos novos movimentos sociais e da ideia segundo o qual as articulações hegemônicas em torno da variedade de posições de sujeito fariam frente à expansão do projeto hegemônico vinculado ao discurso liberal conservador que empreende a criação de um novo "bloco histórico". É importante lembrar que os autores lançaram mão desse argumento diante da onda liberal conservadora que então começava sua difusão hegemônica na política ocidental na década de 1980. Sendo assim, a proposta dos autores é de uma democracia radical que encerre a ideia de contemplar as cadeias de equivalência entre as distintas lutas contra a opressão na formação de uma articulação hegemônica de caráter democrático. Segundo os autores: "la tarea de la izquierda no puede por tanto consistir en renegar de la ideología liberal democrática sino al contrário, en profundizarla y expandirla en la direción de una democracia radicalizada y plural" (LACLAU; MOUFFE, 2004, p. 222). 


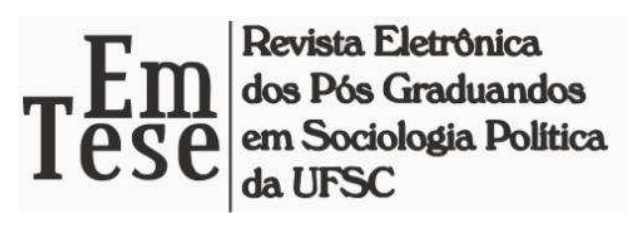

Nessa direção Laclau e Mouffe preconizaram uma radicalização de conceitos do pensador italiano Antônio Gramsci para empreender a proposta de uma democracia radicalizada. A alternativa da esquerda diante da formação de um bloco histórico liberal conservador em expansão é a formação de um bloco histórico democrático e plural capaz de empreender esse embate, o que remonta ao conceito gramsciano de "guerra de posição". De acordo com Laclau e Mouffe "o conceito de 'guerra de posição' implica precisamente a afirmação do caráter processual de toda transformação radical, significa multiplicar os espaços políticos e impedir que o poder seja concentrado em um só ponto como pré-condições de toda transformação realmente democrática da sociedade" (LACLAU; MOUFFE, 2004, p. 223).

Nesse momento é necessário salientar as confluências entre esse momento na teoria dos movimentos sociais e o processo atravessado pela imprensa alternativa. Houve uma trajetória na imprensa alternativa que partiu de uma maior ortodoxia marxista com os jornais da linhagem política e alcançou um momento caracterizado pela diversificação temática e pelo acúmulo de militância entre os jornalistas, como comprovam alguns dos periódicos feministas.

Esse diálogo entre imprensa alternativa e os desdobramentos das teorias dos movimentos sociais pode ser verificado no período de abertura política e na influência que exerceu sobre a atuação política de intelectuais e jornalistas em fins de 1980. A diversificação temática nos alternativos, a institucionalização dos movimentos sociais de vários matizes acompanhada pela saída de muitos partidos da condição de clandestinidade e retomada da atividade política oficial repercutiram negativamente na imprensa alternativa.

Segundo Kucinski, a abertura política e a retomada da articulação partidária em espaços oficiais não clandestinos em torno dos partidos teve como consequência a institucionalização do engajamento jornalístico. O que ocorreu naquele momento foi um processo de institucionalização dos movimentos populares e dos partidos de oposição e por consequência também da atividade jornalística alternativa. A partir das greves do ABC em 1978 e 1979 houve uma tomada dos sindicatos pelas forças de esquerda e também o estabelecimento de entidades representativas vinculadas aos movimentos populares apoiados pela Comissão Pastoral da Terra e pela CUT (Central Única dos Trabalhadores), bem como outras entidades da sociedade civil. Em tais entidades 


\section{$\mathrm{Em}$ \\ Tese da UFSC}

aglutinaram vários jornalistas a fim de produzirem jornais, boletins e os próprios órgãos de sindicatos e partidos.

A partir da década de 1980 - já no fim do ciclo alternativo - apareceram os jornais ligados aos movimentos sociais de base e isso ocasionou uma nova modalidade de engajamento jornalístico e articulação entre jornalismo e política, o que Kucisnki vinculou em seu trabalho à mudança de lugar social por parte dos jornalistas. De acordo com as reflexões do autor, o processo de institucionalização do jornalismo crítico acontece a partir do vínculo estabelecido entre a atividade e os sindicatos, partidos e movimentos populares apoiados pela Igreja Católica e sociedade civil. Kucinski sublinha o fato de que nesse período eram outras gerações engajadas e outra ética que norteava os projetos e em virtude disso se enfraqueceram os coletivos dos jornais alternativos e o imaginário político que os orientava. Sendo assim, destituídos da articulação originária da imprensa alternativa os jornais e jornalistas tornam-se apenas veículos de defesa de interesses cooperativistas ou institucionais. Nesse novo lugar social não há autonomia e o jornalista não é sujeito do processo (KUCINSKI, 2003, p. 27).

O estudo de Evelina Dagnino é esclarecedor quanto ao período de redemocratização. A autora se concentrou no processo de construção democrática na América Latina com ênfase na disputa existente entre o projeto político neoliberal e democrático participativo. De acordo com a pesquisadora, a adoção de projetos políticos de feição neoliberal em países latino-americanos ocasionou uma série de impactos como a transferência das responsabilidades sociais do Estado pra a sociedade civil e para o setor privado ao lado das privatizações das empresas estatais, ações consideradas fundamentais para o enxugamento e a redução do Estado (DAGNINO, 2006, p. 54). Em decorrência desse processo a autora aponta a marginalização dos movimentos sociais resultado da crescente identificação entre a sociedade civil e ONG's (Organizações Não Governamentais), onde o significado da expressão "sociedade civil" se restringe cada vez mais a designar apenas essas organizações, quando não em mero sinônimo de "terceiro setor" (DAGNINO, 2006, p. 56).

A análise dos dados citados é intuitiva para a reflexão sobre o declínio da imprensa alternativa em virtude da consolidação de uma nova conjuntura política. A democratização propiciou a ascensão de ativistas políticos da sociedade civil para o 


\section{$\mathrm{Em}$ \\ Tese}

Estado promovendo a institucionalização de muitos movimentos sociais. Por analogia podemos inferir que o processo de abertura política e redemocratização foi concomitante ao esvaziamento dos jornais alternativos em época de exceção e repovoamento da grande imprensa com aparecimento de jornalistas agora na condição de profissionais e não mais de ativistas políticos. Podemos conjecturar assim que o fim da imprensa alternativa seria uma consequência da difusão de políticas neoliberais, do enfraquecimento e despolitização da sociedade civil. Entretanto, não podemos negligenciar que o declínio da imprensa alternativa também foi simultâneo às mudanças ocorridas no mercado profissional jornalístico que envolveu a profissionalização e a tecnicização da profissão de jornalista. A partir das décadas de 80 e 90 houve um aumento no número de jornalistas diplomados nas redações como desdobramento da promulgação do Decreto-Lei $n^{\circ}$ 972, de 17 de outubro de 1969 que implantava a exigência do diploma para o exercício da profissão. A partir de então, o engajamento político deixou de estar atrelado à atividade jornalística.

Em um interessante prefácio escrito por Carlos Nelson Coutinho ao livro de Giovanni Semeraro sobre a sociedade civil em Gramsci, pode-se averiguar o quanto a dicotomia entre Estado e sociedade civil marcou a produção intelectual nos anos 1970. Nesse período, segundo Coutinho, em função da influência de um contexto de luta contra a ditadura, o par conceitual Estado/Sociedade Civil "que forma em Gramsci uma unidade na diversidade", sofreu as consequências de uma má interpretação. Assim, a sociedade civil tornou-se algo essencialmente positivo enquanto sinônimo de tudo aquilo que se contrapunha ao Estado, por sua vez Estado passou a ser considerado algo fortemente marcado pela negatividade. Para Coutinho, a situação complicou-se ao final dos anos 80 quando a ideologia neoliberal em ascensão apropriou-se desse maniqueísmo para demonizar o que provém do Estado, ainda que seja um Estado de direito, e para fazer apologia acrítica de uma sociedade civil despolitizada convertida num mítico "terceiro setor" situado para além do Estado e do mercado (SEMERARO apud COUTINHO, 1999, p. 10).

A adoção de práticas neoliberais no período posterior à redemocratização operou um afastamento da sociedade civil da atividade política. Ações envolvendo cidadania e participação em políticas públicas tornaram-se encargos de ONG's e fundações empresariais reunidas sob o signo do terceiro setor. A marginalização dos 


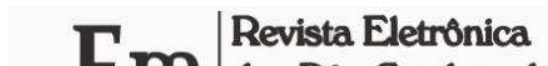 da UFSC}

movimentos sociais e a despolitização foram uma consequência desse processo. É nesse sentido que podemos inferir que a imprensa alternativa, enquanto um movimento social, assim como os demais sofreu com as consequências do momento pós-democratização. Entretanto, é possível conjecturar que a conjuntura política não seja a única responsável pelo declínio da imprensa alternativa como movimento social.

\section{SILÊNCIO DOS INTELECTUAIS E DESPOLITIZAÇÃO}

A despolitização da sociedade civil e a institucionalização dos movimentos sociais foram simultâneos ao declínio da imprensa alternativa aqui considerada um movimento social. Cabe indagar se o seu desaparecimento marcou o fim da atuação do jornalista como intelectual e ativista político. Pensar nesses termos significa analisar o movimento social da imprensa alternativa sob a perspectiva de seus protagonistas.

A discussão a respeito do papel do intelectual conquistou grande dimensão nos anos de 1970. Nenhum teórico influenciou tanto os intelectuais do início de 1970 quanto Gramsci. Grande parte da produção intelectual e cultural do período foi influenciada pelas teses do intelectual italiano, o que pode ser exemplificado pelo recorrente emprego da expressão "intelectual orgânico" que se tornou corrente para designar o trabalhador intelectual ou pensador que se dispõe a contribuir para a formação de uma consciência política no interior da classe operária. Pode-se pressupor que na época a diretriz fosse estabelecer uma hegemonia cultural. Segundo as reflexões de Gramsci, para gerar revolução no Ocidente seria necessário desenvolver a própria consciência dos trabalhadores e para criar a cultura da classe trabalhadora ou um bloco de forças históricas em torno dessa, seria necessário recorrer a um núcleo de "intelectuais orgânicos", desenvolvido a partir da classe trabalhadora para complementar os intelectuais "tradicionais" do partido (TARROW, 2009, p. 30). A solução gramsciana para combater a hegemonia cultural burguesa era produzir entre os trabalhadores um consenso em torno do partido para que eles tomassem consciência de sua própria condição social. O papel do intelectual era empreender a edificação cultural hegemônica na sociedade civil, considerada uma arena privilegiada da luta de classe, uma esfera do ser social, onde se dá uma intensa luta pela hegemonia (SEMERARO 


\section{$\mathrm{Em}^{20 m a n}$ da UFSC}

apud COUTINHO, 1999, p. 10).

$\mathrm{Na}$ coletânea de textos "Intelectuais e a Organização da Cultura", Gramsci procurou analisar o processo de formação histórica dos intelectuais. O pensador italiano distinguiu duas categorias de intelectuais: tradicionais e orgânicos. Os tradicionais são uma categoria de intelectuais que remete a um período anterior ao capitalismo. Estes se consideram independentes, a exemplo dos eclesiásticos. Por sua vez, os intelectuais orgânicos são aqueles que nascem com a sociedade capitalista e estão organicamente ligados à classe que lhes deu origem. Os orgânicos seriam aqueles que estão a serviço de sua classe e exercem atividades capazes de organizar a sociedade em geral criando condições favoráveis para manutenção da hegemonia. Gramsci dirige-se àqueles jornalistas que creem ser os verdadeiros intelectuais por terem em mente o tipo tradicional de intelectual, isto é, aquele que é fornecido pelo literato, pelo filósofo, pelo artista. Para ele, no mundo moderno, a educação técnica atrelada ao trabalho industrial deve constituir a base do novo tipo de intelectual, aquele que domina as técnicas e está inextrincavelmente ligado aos aspectos práticos do mundo da vida. Segundo o estudioso italiano, "o modo de ser do novo intelectual não pode mais consistir na eloquência, motor exterior e momentâneo dos afetos e das paixões, mas num imiscuir-se ativamente na vida prática" (GRAMSCI, 1978, p. 8).

Os jornais alternativos apoiados em frentes de partidos se propunham a construir uma consciência coletiva homogênea através da prática de um jornalismo integral inserido no cotidiano social e na vida prática. Segundo Kucinski, a definição de jornalismo integral de Gramsci consiste naquele jornalismo que vai além da mera satisfação das necessidades aparentes de seu público ou de seus jornalistas, é o jornalismo capaz de criar e desenvolver essas necessidades e ampliar seu público. Para Gramsci o jornalismo integral só podia ser praticado se o jornal fosse uma entidade em si mesma, geradora do seu próprio conhecimento, e portadora de uma ética específica, embora ligada aos grandes movimentos sociais. Não poderia, portanto, ser mera correia de transmissão de um partido ou de um comitê central (KUCINSKI, 2003, p. 122).

Considerando as características da linhagem política de jornais alternativos pode-se inferir que as diretrizes do pensamento de Gramsci estavam presentes em suas linhas editoriais. Assim, o desaparecimento da figura do jornalista que se coloca na posição de "intelectual orgânico" pode estar associada ao enfraquecimento dos 


\section{$\mathrm{Em}$

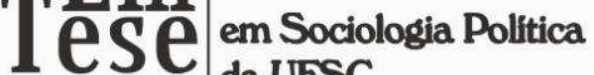 da UFSC}

alternativos e também ao processo de mudanças no mercado jornalístico que, por sua vez, teve repercussões diretas na identidade profissional.

Assim, tem-se que o surgimento de algumas vertentes teóricas revisionistas foi igualmente simultâneo a uma profunda transformação na profissão de jornalista. Contrapontos foram levantados com relação ao ideário que envolve conceitos estanques como "sujeito histórico". A desmistificação da ideia de um sujeito político privilegiado foi seguida pela desmistificação do conceito de "lutas de classe" considerado insuficiente diante da complexidade das posições de sujeito na contemporaneidade o que repercutiu na militância que agia nos bastidores dos jornais alternativos da frente política.

No âmbito profissional, atualmente se pode verificar a existência de espaços relativamente definidos para a atuação de jornalistas, intelectuais e políticos. A redemocratização oficializou a atuação dos partidos políticos. Os intelectuais ingressaram em carreiras nas universidades e no ofício da produção cultural. Os jornalistas se tornaram profissionais da produção da notícia. O conjunto desses acontecimentos sinaliza para o fato de que a profissionalização dessas formas de atuação profissional não pode ser negligenciada como parte do processo de mudança ocorrido nas últimas décadas.

A despeito da sobrevivência de alguns jornais que se declaram alternativos na atualidade, a atividade em torno dessa modalidade de periódicos declinou se comparada a efervescência da imprensa alternativa dos anos 70 e 80 . O motivo está na peculiar conjunção de fatores que deu origem aos periódicos e que se enfraqueceu a partir dos anos 90. Nesse sentido, é impossível desconsiderar o contexto de agitação dos movimentos sociais nos anos 70 no qual surgiram os periódicos da imprensa alternativa, uma vez que esses jornais deram voz e visibilidade para muitos desses movimentos. Entretanto, há motivos para o enfraquecimento desses periódicos que estão além da saída dos militantes dos bastidores e das redações dos alternativos. As transformações na profissão de jornalista compreendem um fenômeno do qual o declínio do jornalismo engajado como traço identitário da figura do jornalista é apenas um dos fatores que compõem o atual cenário de mudanças na produção cultural. 


\section{REFERÊNCIAS}

COUTINHO, Carlos Nelson. Prefácio. In: SEMERARO, Giovanni. Gramsci e a sociedade civil: cultura e educação para a democracia. Petrópolis, RJ: Vozes, 1999. p. 912.

DAGNINO, Evelina; OLVER, Alberto J.; PANFICHI, Aldo. A disputa pela construção democrática na América Latina. São Paulo: Paz e Terra, 2006.

GOHN, Maria da Glória. Teoria dos movimentos sociais: paradigmas clássicos e contemporâneos. São Paulo: Loyola, 1997.

GRAMSCI, Antônio. Os intelectuais e a organização da cultura. Rio de Janeiro: Civilização Brasileira, 1978.

KUCINSKI, Bernardo. Jornalistas e revolucionários: nos tempos da imprensa alternativa. São Paulo: Editora da Universidade de São Paulo, 2003.

LACLAU, Ernesto.;MOUFFE, Chantal. Hegemonia y estratégia socialista: hacia una radicalización de la democracia. Argentina: Fondo de Cultura Económica de Argentina S.A., 2004.

LACLAU, Ernesto. Os novos movimentos sociais e a pluralidade do social. Revista Brasileira de Ciências Sociais, v. 1, n. 2, 1986, p. 41-47.

TARROW, Sidney. O poder em movimento: movimentos sociais e confronto político. Petrópolis, Rio de Janeiro: Vozes, 2009. 


\title{
MOBILIZAÇÃO JORNALÍSTICA NOS ANOS 70: A IMPRENSA ALTERNATIVA COMO MOVIMENTO SOCIAL
}

\begin{abstract}
Resumo: O presente artigo tem como objetivo o apontamento de analogias entre a história da imprensa alternativa no Brasil e a trajetória das teorias dos movimentos sociais a fim considerar a mobilização em torno dos jornais alternativos como um movimento social. Propõe-se um diálogo entre a obra Jornalistas e Revolucionários, de autoria de Bernardo Kucinski e o pensamento de alguns autores representativos das teorias dos movimentos. Jornalistas e Revolucionários trata de realizar um resgate histórico dos jornais alternativos e aborda questões relativas ao surgimento, expansão e declínio do ciclo alternativo. O objetivo desse artigo é analisar a imprensa alternativa sob a luz das teorias dos movimentos sociais ao indicar as confluências entre essa modalidade de imprensa e determinadas vertentes teóricas. No intercurso desse estudo exemplifico como a conjuntura de redemocratização no Brasil, bem como a progressiva profissionalização de figuras como o jornalista, o político e o intelectual contribuíram para o recondicionamento desses profissionais em um contexto democrático. Em suma, abordo o histórico do desenvolvimento das teorias dos movimentos sociais em sinergia com a trajetória da imprensa alternativa e seus protagonistas a fim de realçar a sintonia existente entre uma história das ideias e uma história das ações.
\end{abstract}

Palavras-Chave: Imprensa Alternativa. Teorias dos Movimentos Sociais. História da Imprensa. Redemocratização.

\section{JOURNALISTIC MOBILIZATION IN THE 70S: THE ALTERNATIVE PRESS AS SOCIAL MOVEMENT}

\begin{abstract}
This article aims at pointing analogies between the history of the alternative press in Brazil and the trajectory of the theories of social movements to consider the mobilization around the alternative newspapers as a social movement. We propose a dialogue between the work Jornalistas e Revolucionários, written by Bernardo Kucinski and the thought of some representative authors of the theories of movement. The work Jornalistas e Revolucionários does an historical rescue of alternative journals and discuss the emergence, expansion and decline of the alternative cycle. The aim of this paper is to analyze the alternative press in the light of the theories of social movements and to indicate the confluences between this form of press and certain theoretical aspects. In this study we exemplify how the democratization of conditions in Brazil, and the progressive professionalization of figures such as the journalist, the political and the intellectual contributed to readjust these professionals to a democratic context. In summary, we discuss the historical development of theories of social movements in synergy with the path of the alternative press and its protagonists in order to point the existing harmony between a history of ideas and a history of actions.
\end{abstract}


1 eSE|l|l|l $\begin{aligned} & \text { Revista Eletrônica } \\ & \text { dos Pós Graduandos } \\ & \text { em Sociologia Política } \\ & \text { da UFSC }\end{aligned}$

Keywords: Alternative Press. Theories of Social Movements. Press story. Democratization.

Recebido em: 11 de setembro de 2014

Aceito para publicação em: 18 de novembro de 2014 